\title{
Prediction of $\mathrm{N}$-nitrosamine partition coefficients for de-risking drug substance manufacturing processes
}

\author{
Ian W. Ashworth, ${ }^{\dagger}$ Timothy T. Curran, $\S$ J Gair Ford, $\ddagger$ Simone Tomasi. ., * \\ tChemical Development, Pharmaceutical Technology \& Development, Operations, \\ AstraZeneca, Macclesfield, UK. \\ \$Process Chemistry, Vertex Pharmaceuticals, Boston, Massachusetts, USA. \\ ‡ Regulatory CMC, Global Regulatory Excellence, AstraZeneca, Macclesfield, UK. \\ Simone.tomasi@astrazeneca.com
}

Supporting Information

Derivation of Equations 8 and 9

Nitrosamine LogP Predictions

Calculated nitrosamine LogP values in mol fraction terms for benchmarking

Sample LogP calculation including input, tabular output and cosmo file

$$
\text { Page }
$$

S2

Separate file

(Nitrosamine LogP predictions full.xlsx)

Separate file

(Nitrosamine LogP benchmarking COSMO vs EXP.xlsx)

Sample_LogP_FINE16.zip 


\section{Derivation of Equations 8 \& 9}

Considering the partitioning of an impurity $(\mathrm{Imp})$ and product $(\mathrm{Pr})$ between water and a water immiscible solvent (Scheme S1).

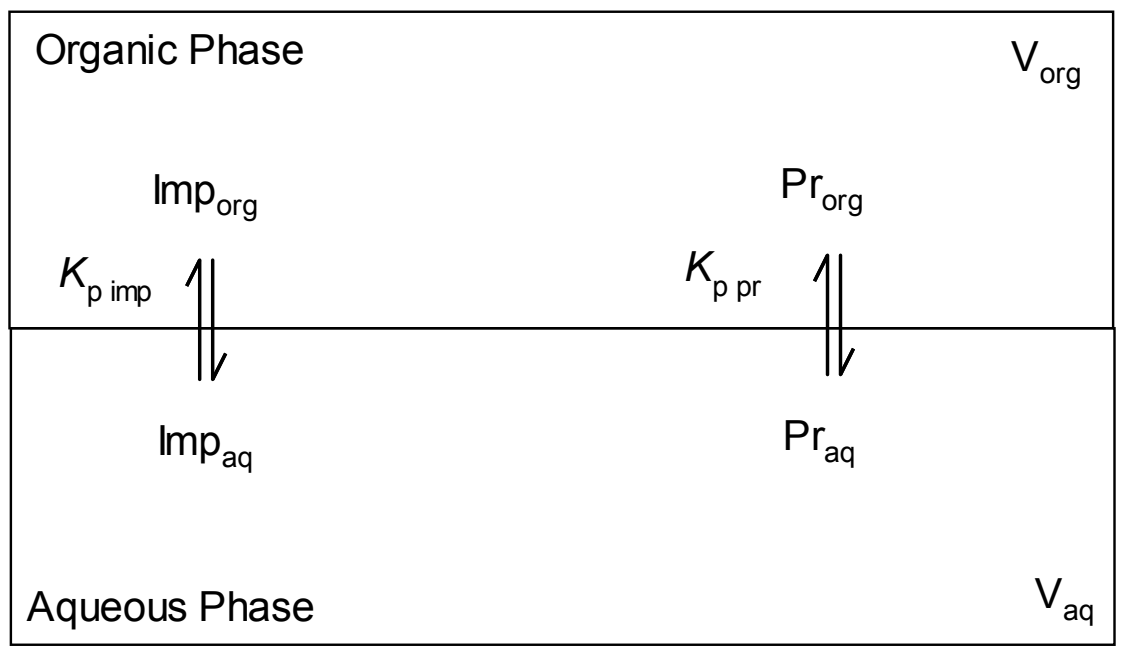

Scheme S1 - Partition of a reaction product and impurity between water and an immiscible solvent.

Definitions:

$$
K_{p}=\frac{[X]_{\text {org }}}{[X]_{a q}}, V_{R}=\frac{V_{\text {org }}}{V_{a q}}
$$

$[X]_{T \text { org }}=$ the $[X]$ that would arise if it was all in the organic phase

The fraction of a compound presence in the aqueous phase may be calculated by using equation $\mathrm{S} 1 .{ }^{1}$ The term $f_{N}$ in equation $\mathrm{S} 1$ is the fraction of the molecule in the neutral form at a particular $\mathrm{pH}$ and is by definition 1 for compounds that do not ionise. For compounds that ionise this can be calculated from the compounds dissociation constants $\left(K_{\mathrm{a}} \mathrm{s}\right)$ and the $\mathrm{pH} .{ }^{1}$

$$
\text { Aq. Fraction extracted }=\text { Aq. } f_{\text {Ext }}=\frac{1}{\left(1+K_{p} V_{R} f_{N}\right)}
$$

Assuming that the impurity and product start in the organic phase it is possible to define an initial level (equation S2) and a level at equilibrium in each phase (equations S3 \& S4). The common volume terms implicit in the concentrations in these equations means that the levels are actually the ratio of the number of moles present in a phase.

$$
\text { Initial level }=L_{0 \text { org }}=\frac{[\mathrm{Imp}]_{0 \text { org }}}{[\mathrm{Pr}]_{0 \text { org }}}=\frac{[\mathrm{Imp}]_{\text {T org }}}{[\mathrm{Pr}]_{\text {T org }}}=\frac{\text { moles }_{\text {imp }}}{\text { moles }_{\text {pr }}}(S 2)
$$




$$
\begin{aligned}
& \text { Equilibrium level organic }=L_{e \text { org }}=\frac{[\operatorname{Imp}]_{\text {e org }}}{[\mathrm{Pr}]_{\text {e org }}} \\
& \text { Equilibrium level aqueous }=L_{e \text { aq }}=\frac{[\operatorname{Imp}]_{\text {e aq }}}{[\mathrm{Pr}]_{\text {e } a q}}
\end{aligned}
$$

There are now two situations that need to be considered. Firstly, the purge provided by the extraction when the majority of the product remains in the organic phase. The purge factor is defined by equation S5. The equilibrium level of the impurity in the organic phase is given by equation S3 and the equilibrium concentration of the impurity and product can be calculated using equation $\mathrm{S} 1$ and the theoretical maximum concentration if all of the compound was in the organic phase, $[X]_{\text {T org }}$ (equations S6 \& S7)

$$
\begin{gathered}
\text { Purge factor }=\frac{L_{0 \text { org }}}{L_{\text {e org }}}(S 5) \\
{[\text { Imp }]_{\text {e org }}=[\operatorname{Imp}]_{\text {T org }}\left(1-A q f_{\text {Ext imp }}\right)} \\
{[\mathrm{Pr}]_{\text {e org }}=[\mathrm{Pr}]_{\text {T org }}\left(1-A q f_{\text {Ext pr }}\right)}
\end{gathered}
$$

Substituting into equation S5 from equations S2 \& S3 and from S6 \& S7 into S3 and rearranging gives equation 8 .

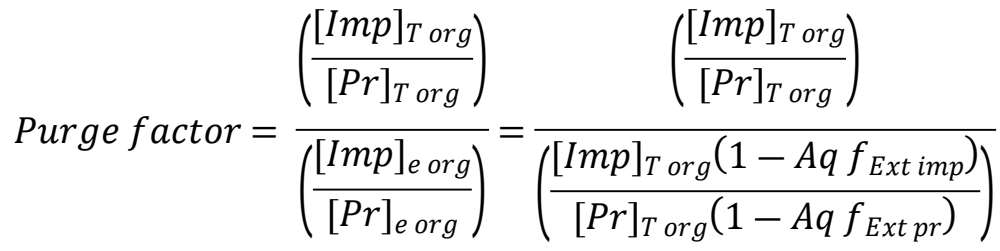

$$
\begin{aligned}
& =>\text { Purge factor }=\frac{1}{\left(\frac{1-A q f_{\text {Ext imp }}}{1-A q f_{\text {Ext } p r}}\right)} \\
& =>\text { Purge factor }=\frac{1-A q f_{\text {Ext } p r}}{1-A q f_{\text {Ext imp }}}=\text { Equation } 8
\end{aligned}
$$

The second scenario is where the product extracts into the aqueous phase and leaves the majority of the impurity in the organic phase. In this case the purge factor is defined by equation S8 and the equilibrium concentrations of the product and impurity in the aqueous phase are given by equation $S 9 \&$ S10.

$$
\text { Purge factor }=\frac{L_{0 \text { org }}}{L_{\text {e aq }}}
$$




$$
\begin{aligned}
{[\operatorname{Imp}]_{\text {e aq }} } & =[\operatorname{Imp}]_{\text {T aq }} \times A q f_{\text {Ext imp }}(S 9) \\
{[\mathrm{Pr}]_{\text {e aq }} } & =[\mathrm{Pr}]_{\text {T aq }} \times A q f_{\text {Ext pr }}(\mathrm{S} 10)
\end{aligned}
$$

Substituting into equation S8 from equations S2 \& S4 and from S9 \& S10 into S4 and rearranging gives equation 9 .

$$
\begin{aligned}
& \text { Purge factor }=\frac{\left(\frac{[\operatorname{Imp}]_{\text {Torg }}}{[\text { Pr }]_{\text {Torg }}}\right)}{\left(\frac{[\operatorname{Imp}]_{\text {e aq }}}{[\text { Pr }]_{\text {e } a q}}\right)}=\frac{\left(\frac{[\operatorname{Imp}]_{\text {Torg }}}{[\text { Pr }]_{\text {Torg }}}\right)}{\left(\frac{[\operatorname{Imp}]_{\text {T aq }} \times A q f_{\text {Ext imp }}}{[\text { Pr }]_{\text {T aq }} \times A q f_{\text {Ext } p r}}\right)} \\
& =>\text { Purge factor }=\left(\frac{[\operatorname{Imp}]_{T \text { org }}}{[\text { Pr }]_{\text {Torg }}}\right)\left(\frac{[P r]_{T a q} \times A q f_{\text {Ext pr }}}{[\operatorname{Imp}]_{T \text { aq }} \times A q f_{\text {Ext imp }}}\right) \\
& =>\text { Purge factor }=\frac{A q f_{\text {Ext } p r}}{A q f_{\text {Ext imp }}}=\text { Equation } 9
\end{aligned}
$$

\section{References}

1. Ashworth, I. W.; Meadows, R. E. A General Liquid-Liquid Partitioning Equation and Its Consequences: Learning from the $\mathrm{pH}$ Dependent Extraction of a Pharmaceutical Intermediate. J. Org. Chem. 2018, 83, 4270-4274. 